Article

\title{
Evaluation of Large-Scale Production of Chitosan Microbeads Modified with Nanoparticles Based on Exergy Analysis
}

\author{
Samir Meramo-Hurtado® ${ }^{\circledR}$, Adriana Herrera-Barros and Ángel González-Delgado * \\ Nanomaterials and Computer Aided Process Engineering Research Group (NIPAC), University of Cartagena, \\ Cartagena 130015, Colombia; smeramoh@unicartagena.edu.co (S.M.-H.); \\ aherrerab2@unicartagena.edu.co (A.H.-B.) \\ * Correspondence: agonzalezd1@unicartagena.edu.co
}

Received: 23 January 2019; Accepted: 22 March 2019; Published: 28 March 2019

check for updates

\begin{abstract}
Novel technologies for bio-adsorbent production are being evaluated on the lab-scale in order to find the most adequate processing alternative under technical parameters. However, the poor energy efficiency of promising technologies can be a drawback for large-scale production of these bio-adsorbents. In this work, exergy analysis was used as a computer-aided tool to evaluate from the energy point of view, the behavior of three bio-adsorbent production topologies at large scale for obtaining chitosan microbeads modified with magnetic and photocatalytic nanoparticles. The routes were modeled using an industrial process simulation software, based on experimental results and information reported in literature. Mass, energy and exergy balances were performed for each alternative, physical and chemical exergies of streams and chemical species were calculated according to the thermodynamic properties of biomass components and operating conditions of stages. Exergy efficiencies, total process irreversibilities, energy consumption, and exergy destruction were calculated for all routes. Route 2 presents the highest process irreversibilities and route 3 has the highest exergy of utilities. Exergy efficiencies were similar for all simulated cases, which did not allow to choose the best alternative under energy viewpoint. Exergy sinks for each topology were detected. As values of exergy efficiency were under $3 \%$, it was shown that there are process improvement opportunities in product drying stages and washing water recovery for the three routes.
\end{abstract}

Keywords: bio-adsorbents; exergy analysis; chitosan microbeads; nanoparticles

\section{Introduction}

Nowadays, there is an increasing interest in developing sustainable and green-chemistry-based ways to synthesize novel materials for applications in emerging industries. Industrial wastewater treatment is a major global problem, mainly due to the restricted quantities of water that can be re-used along with the high cost of purification. In recent years, appropriate technologies for the treatment of wastewater and other effluents have raised great interest due to more strict laws and regulations [1]. The literature reports a variety of processes to water treatment and there are a lot of technologies used for this purpose. Among these methods, adsorption stands out as an effective, efficient and low-cost technology [2]. The adsorbents may be of mineral, organic or biological origin and are selected according to their applications. Polymeric adsorbents have been widely used to remove organic pollutants from industrial wastewater, but in recent years, the use of adsorbents produced from biomasses, organic residues and biopolymers have attracted interest due to its high availability and environmental issues related to disposal of residual biomasses and wastes [3]. In this sense, chitosan-based adsorbents have been evaluated showing high removal yield for several substances such as heavy metals, polycyclic aromatic hydrocarbons, among others [4]. 
Green chemistry is related to a new idea which has developed in the industry and research contexts as a natural evolution of pollution-prevention strategies [5]. The use of these types of processes brings the concept of developing chemical plants that can reduce waste generation and the resource demands. Recently, the green chemistry concept is also related to those processes that use smaller amounts of energy maintaining process yield/efficiency while providing reasonably market-valuable products [6]. On the other hand, nanotechnology is an innovative science/field associated with the manipulation of components and materials at the atomic/molecular scale and explains the behavior of these substances when used on the nanoscale. Recently, metal oxide nanoparticles have attracted interested by their potential application in different fields [7].

Modification of bio-adsorbents produced from natural polymers as chitosan microbeads with chemical species as thiourea or magnetite nanoparticles gives to these materials a higher adsorption capacity and selectivity to several heavy metals and liquid hydrocarbons, and higher efficiency in recovery processes via magnetic field application, which was studied at the lab-scale [8], however, the behavior at large scale of these emerging technologies is unknown, so the computer-aided simulation of these technologies at large-scale is relevant for further industrial applications [9].

Biomass-based processing technologies (and many chemical processes) commonly require huge amounts of energy and water, therefore, there are some published studies addressing the application of exergy analysis to measure the process performance from an energy viewpoint. Ojeda et al. [10] applied the exergy analysis to assess process alternatives for producing ethanol from lignocellulosic biomass. Peralta-Ruiz et al. [11] used exergy analysis as a tool for screening process alternatives for microalgae oil extraction. Aghbashlo et al. [12] applied an exergy analysis of a lignocellulosic-based biorefinery along with a sugarcane mill for simultaneous lactic acid and electricity production. Meramo-Hurtado et al. [13] developed an exergy analysis of bioethanol production from rice residues, the results for this study showing that pretreatment stage was the unit with the lowest exergy efficiency. They pointed out that this subprocess can be potentially improved to obtain a better energy performance. Restrepo-Serna et al. [14] developed a study related to the energy efficiency of various biorefinery schemes using sugarcane bagasse as raw material. They performed the assessment based on process simulation and exergy analysis, so it is shown in these studies that exergy analysis can be considered a useful evaluation instrument for the diagnosis of novel technologies involving sustainability goals.

In this work, three production processes for chitosan microbeads modified with nanoparticles were evaluated using exergy analysis as an instrument for screening design alternatives and as a decision-making tool for evaluation of novel technologies from energy viewpoint. Indicators as exergy efficiency, total irreversibilities, exergy utilities, and exergy destruction were determined for each processing alternative evaluated.

\section{Materials and Methods}

In this study, chitosan obtained from shrimp exoskeletons is used as feedstock to synthesize bio-adsorbents which are further modified with nanoparticles. Chitosan is a polymer present in many organic structures in Nature. It is commonly obtained from crustacean wastes through chitin deacetylation techniques [15]. The design and modeling of the processing routes for bio-adsorbents production is developed using a computer-aided process engineering software. This tool requires process information as mass and energy balances, operational conditions, reaction yields, among others. It is important to point out that the information required for the simulations were obtained from literature and experimental results previously published by the authors [16]. Another issue that must be considered is the input of an adequate thermodynamic model which allows estimating most accurate physical-chemical properties of the substances. The simulations give the extended energy and mass balances considering the operational conditions and processing routes of each design. The above parameters are important due to their uses to perform the exergy analysis for each alternative. Finally, exergy indicators are evaluated to compare each chitosan microbeads processing technology with the aim to identify improvement opportunities and screen the most suitable design from an exergy basis. 


\subsection{Processes Simulation}

Process simulation mainly implies selecting chemical components used in the process, choosing an appropriate thermodynamic model, setting processing capacity, using suitable operating units and setting up input conditions such as mass flow rates, temperature, pressure, among others [17]. For the simulation of large-scale production processes of chitosan microbeads was used the industrial process software Aspen Plus, the chemical species required for the simulations were taken from the software database. For those compounds which are not available in the software database, molecules were created using the Aspen Property Estimator based on the properties reported for these species in the literature [18]. It was necessary to create components such as titanium isopropoxide and chitosan during the development of this work. The thermodynamic model Non-Random Two Liquids (NRTL) was selected for process simulations taking into account its good performance in the prediction of thermodynamic properties for polar/non-polar mixtures.

\subsubsection{Process 1: Production of Chitosan Microbeads Modified with $\mathrm{TiO}_{2}$ Nanoparticles via Green Chemistry}

The production process of chitosan microbeads modified with $\mathrm{TiO}_{2}$ nanoparticles $\left(\mathrm{CMTiO}_{2}\right)$ is developed through three specific subprocesses. The first subprocess is the lemongrass oil extraction where organic compounds such as myrcene, undecyne, neral, among others are obtained based on a green chemistry synthesis. These substances are used as surfactants to guarantee the nanosize of the particles. Lemongrass is first pretreated for cellulosic material removal, then it is sent to drying and crushing to reduce the particle size. Thus, the lemongrass oil is obtained in a liquid-solid extract. The second subprocess is the synthesis of $\mathrm{TiO}_{2}$ nanoparticles. This stage uses titanium tetraisopropoxide (TTIP) as a precursor for $\mathrm{TiO}_{2}$ nanoparticles through hydrolysis reactions. Propanol is formed as a by-product of the reaction. Hydrolysis reaction stoichiometry is described as follows:

$$
\mathrm{Ti}\left(\mathrm{OC}_{3} \mathrm{H}_{7}\right)_{4}+2 \mathrm{H}_{2} \mathrm{O} \rightarrow \mathrm{TiO}_{2}+4 \mathrm{C}_{3} \mathrm{H}_{7} \mathrm{OH}
$$

As mentioned earlier, this stage involves the formation of $\mathrm{TiO}_{2}$ nanoparticles via hydrolysis of TTIP. This substance is first diluted to a concentration of $100 \mathrm{mM}$ under controlled conditions and sent to the hydrolysis reactor system. On the other hand, the oil extract (obtained from the first subprocess) is added and mixed with the main stream in the reactor [9]. Figure 1 shows the process diagram for the large-scale production of chitosan microbeads modified with $\mathrm{TiO}_{2}$ nanoparticles. After $\mathrm{TiO}_{2}$ synthesis the main stream is sent to a separation train composed of three washing units where the $\mathrm{pH}$ is stabilized. In the second unit, ethanol is used for washing, while for the first- and third-units water is used. In this separation stage, moisture content of the product is reduced. Finally, the product is sent to a drying unit to obtain the bio-adsorbents with water content equal to zero. The third subprocess begins after $\mathrm{TiO}_{2}$ nanoparticles formation. Chitosan microbeads are prepared from chitosan (main raw material). In the first tank, a chitosan dissolution is prepared at a concentration of $2 \mathrm{w} / \mathrm{v} \%$. The solution is mixed in a second vessel with acetic acid $(2 \mathrm{w} / \mathrm{v} \%)$ obtaining a chitosan gel solution. This gel mixture is sent to another mixing stage where $\mathrm{TiO}_{2}$ nanoparticles are added. The mass ratio between chitosan and $\mathrm{TiO}_{2}$ nanoparticles is 1:2. In this stage, chitosan microbeads modified with $\mathrm{TiO}_{2}$ nanoparticles are formed. For product formation is necessary to set alkaline conditions, hence, $\mathrm{NaOH}$ (at a concentration of $2.5 \mathrm{M}$ ) is used to reach the $\mathrm{pH}$ required [16]. Finally, the microbeads are physically mixed through an ultrasound-assisted agitation system. It is important to point out that the above procedure is developed at a temperature of $28^{\circ} \mathrm{C}$. The resulting microbeads have high moisture content so it is necessary to perform a separation stage where a train of washing and drying units are used to purify the bio-adsorbents. For all process units the operational pressure is $1 \mathrm{~atm}$. 


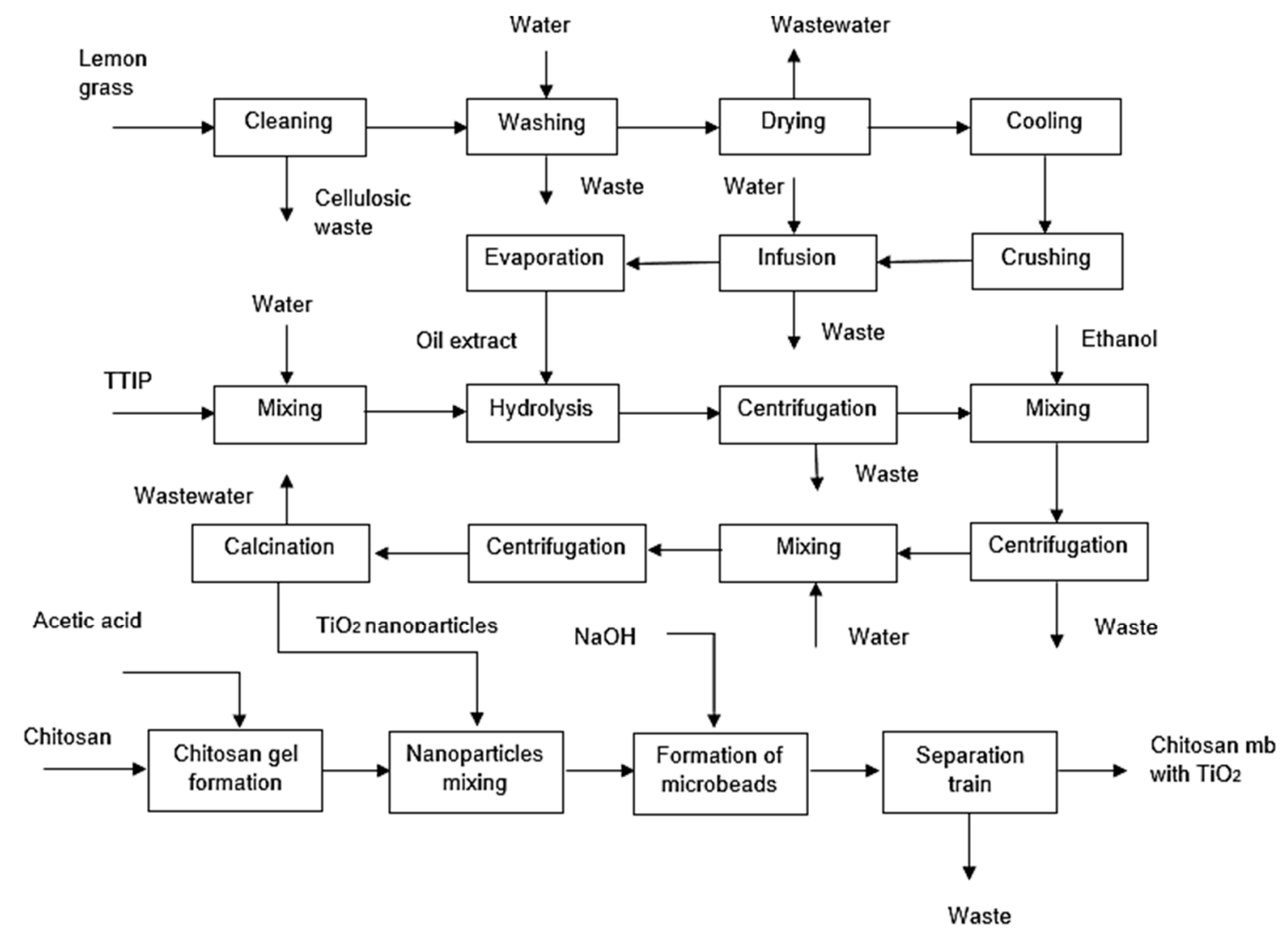

Figure 1. Process diagram of large-scale production of chitosan microbeads modified with $\mathrm{TiO}_{2}$ nanoparticles.

2.1.2. Process 2: Production of Chitosan Microbeads Modified with $\mathrm{TiO}_{2}$ and Magnetite Nanoparticles

Production of chitosan microbeads modified with $\mathrm{TiO}_{2}$ and magnetite nanoparticles $\left(\mathrm{CMTiO}_{2}-\mathrm{Mag}\right)$ is divided into two main subprocesses. Subprocess (1) is related to the synthesis of magnetite nanoparticles while subprocess (2) to the microbeads formation. For magnetite nanoparticles synthesis, the first stage implies the preparation of iron oxides solutions $\left(\mathrm{FeCl}_{3} \cdot \mathrm{H}_{2} \mathrm{O}\right.$ and $\left.\mathrm{FeCl}_{2} \cdot 4 \mathrm{H}_{2} \mathrm{O}\right)$ at a temperature of $301.15 \mathrm{~K}$ [19]. Subsequently, these solutions are mixed and sent to a heat exchanger unit to reach a temperature of $353.15 \mathrm{~K}$. Thus, the resulting stream is fed into the iron oxides reactor where magnetite is produced along with $\mathrm{NaCl}$ and $\mathrm{H}_{2} \mathrm{O}$. In order to form the nanoparticles, $\mathrm{NaOH}$ is added at a concentration of $2 \% \mathrm{v} / \mathrm{v}$. The outlet stream of the reactor is cooled to $301.15 \mathrm{~K}$, and sent to a separation stage. In this stage, the nanoparticles are separated using magnetic fields. The above allows removing non-ferrous material. To reach higher purity, the magnetite nanoparticles are fed into a separation train composed of three consecutive washing units (an analog system used for $\mathrm{CMTiO}_{2}$ process). Finally, the main stream is sent to a furnace unit where the microbeads are completely dried. For the final product, it is desired to obtain a mass ratio for chitosan, $\mathrm{TiO}_{2}$ and magnetite of 2:1:1, respectively. On the other hand, second subprocess $\mathrm{CMTiO}_{2}-\mathrm{Mag}$ alternative is similar to subprocess (3) of $\mathrm{CMTiO}_{2}$ design described in Section 2.1.1 but the modification with magnetite is incorporated after $\mathrm{TiO}_{2}$ nanoparticles modification. Thus, it is important to mention that these modifications are related to physical mixing processes. Figure 2 shows the process diagram for the large-scale production of chitosan microbeads modified with $\mathrm{TiO}_{2}$ and magnetite nanoparticles. 


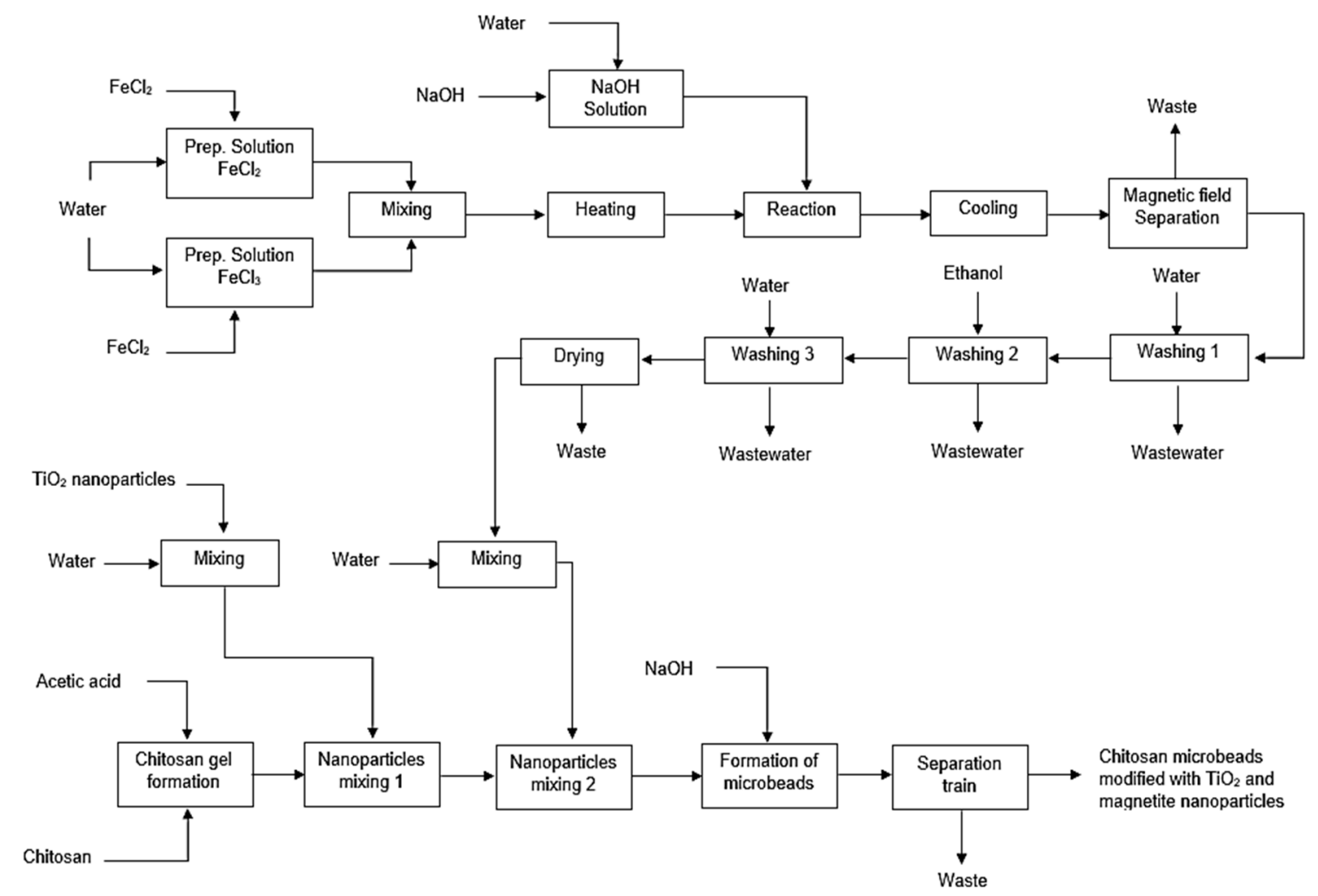

Figure 2. Process diagram of large-scale production of chitosan microbeads modified with $\mathrm{TiO}_{2}$ and magnetite nanoparticles.

\subsubsection{Process 3: Production of Chitosan Microbeads Modified with Thiourea}

The third process evaluated consists in the large-scale production of chitosan microbeads modified with thiourea. In this process, thiourea is mixed with the main stream after chitosan gel formation. The process follows to the microbeads formation using diluted $\mathrm{NaOH}$. Finally, the microbeads are purified through washing and drying stages. The mass ratio for chitosan and thiourea is 1:1. Figure 3 shows the process diagram for the large-scale production of chitosan microbeads modified with thiourea

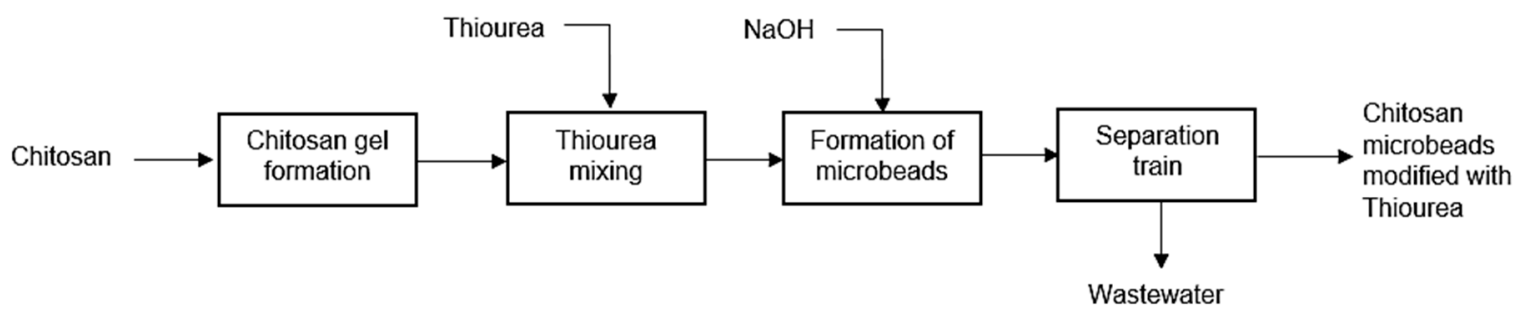

Figure 3. Process diagram of large-scale production of chitosan microbeads modified with thiourea.

\subsection{Exergy Analysis}

Thermodynamics-based tools such as energy analysis, exergy analysis, emergy analysis, among others have been applied for evaluation of industrial systems and thermal energy storage processes [20]. The first and second law of thermodynamics serve as a theoretical basis for energy analysis, along with the calculation of energy efficiencies for the studied processes. However, an energy balance not necessary provides information associated with the energy losses or quantifies the quality of the mass and energy streams of the evaluated routes. Exergy analysis is presented as an alternative tool which allows surpass the limitations of the laws of thermodynamics for a desired process [21]. Exergy analysis also shows the source of energy degradation in a process and can help to optimize an 
operation, a technology or a processing unit [22]. In addition, exergy analysis allows evaluating several process technologies to improve the design of a process. The above means that the exergy analysis is an appropriate tool to assess novel technologies for any chemical process. The exergy is defined as the maximum theoretical useful work that could be obtained from a system that interacts only with the environment. Considering that the exergy of a system depends on the selected state of reference, it is usual to choose standard environmental conditions as the reference state. Based on steady-state conditions, four balance equations have to be addressed to determine work/heat interactions. The first equation is the mass/matter conservation principle given by Equation (1), the second equation refers to the first law of thermodynamics given by Equation (2). The third equation refers to the second law of thermodynamics given by Equation (3):

$$
\begin{gathered}
\sum_{\mathrm{i}}\left(\mathrm{m}_{\mathrm{l}}\right)_{\text {in }}=\sum_{\mathrm{i}}\left(\mathrm{m}_{\mathrm{l}}\right)_{\text {out }} \\
\sum_{\mathrm{i}}\left(\mathrm{m}_{\mathrm{l}} \mathrm{h}_{\mathrm{i}}\right)_{\text {in }}=\sum_{\mathrm{i}}\left(\mathrm{m}_{\mathrm{l}} \mathrm{h}_{\mathrm{i}}\right)_{\text {out }}+\mathrm{Q}-\mathrm{W}=0 \\
\sum_{\mathrm{i}}\left(\mathrm{m}_{\mathrm{l}} \mathrm{S}_{\mathrm{i}}\right)_{\text {in }}=\sum_{\mathrm{i}}\left(\mathrm{m}_{\mathrm{l}} \mathrm{S}_{\mathrm{i}}\right)_{\text {out }}+\sum_{\mathrm{i}} \frac{\mathrm{Q}_{\mathrm{l}}}{\mathrm{T}_{\mathrm{i}}}+\mathrm{Q}-\mathrm{W}=0
\end{gathered}
$$

A fourth equation is addressed to formulate the exergy balance for around the system during a finite time interval given by Equation (4):

$$
\text { Exergy input }- \text { Exergy output }- \text { Exergy consumption = Exergy accumulation }
$$

Exergy consumed is the product between the entropy generated and the environmental temperature, as follows in Equation (5) [9]:

$$
\text { Exergy consumed }=\text { Environmental temperature } x \text { Entropy }
$$

The Equation (4) can be expressed in terms of the mass exergy entering or leaving the system $\left(\mathrm{Ex}_{\text {mass, in }}\right.$ and $\left.\mathrm{Ex}_{\text {mass, out }}\right)$, exergy flow by heat $\left(\mathrm{Ex}_{\text {Heat }}\right)$, exergy flow by work $\left(\mathrm{Ex}_{\text {work }}\right)$, and exergy loss $\left(\mathrm{Ex}_{\text {loss }}\right)$, in mathematical terms as follows:

$$
\mathrm{Ex}_{\text {mass,in }}-\mathrm{Ex}_{\text {mass,out }}+\mathrm{Ex}_{\text {Heat }}-\mathrm{Ex}_{\text {work }}=\mathrm{Ex}_{\text {loss }}
$$

Calculation of exergy flow by mass transfer is shown in Equation (6), it can be defined as a sum of physical exergy $\left(E x_{\text {phy }}\right)$, chemical exergy $\left(E x_{\text {che }}\right)$, potential exergy $\left(E_{\mathrm{pot}}\right)$, and kinetic exergy $\left(\mathrm{Ex}_{\mathrm{kin}}\right)$, according to Equation (7):

$$
\mathrm{Ex}_{\text {mass }}=\mathrm{Ex}_{\mathrm{phy}}+\mathrm{Ex}_{\mathrm{che}}+\mathrm{Ex}_{\mathrm{pot}}+\mathrm{Ex}_{\mathrm{kin}}
$$

The chemical exergy is calculated using the chemical exergy per mole of each component. The estimation of the chemical exergy per mole is performed based on the free energy of formation $\left(\Delta \mathrm{G}_{\mathrm{i}}\right)$ and the specific chemical exergy of each atom presented in the molecule $\left(\mathrm{Ex}_{\mathrm{chem}, \mathrm{j}}\right)$ :

$$
\operatorname{Ex}_{\text {chem }, \mathrm{i}}=\Delta \mathrm{G}_{\mathrm{i}}+\sum_{\mathrm{j}} \mathrm{n}_{\mathrm{ele}} \mathrm{Ex}_{\mathrm{chem}, \mathrm{j}}
$$

The exergy of a heat stream $Q$ is determined by the Carnot factor as follows:

$$
\mathrm{Ex}_{\text {heat }}=\mathrm{Q}+\left(1-\frac{\mathrm{T}_{\mathrm{o}}}{\mathrm{T}}\right)
$$


where $T_{0}$ is the environment (or reference) temperature and $T$ is the temperature at which $Q$ is available. Finally, the last term in the exergy balance $\left(\mathrm{Ex}_{\text {work }}\right)$ is associated for losses by work. Equation (10) gives the relation between these parameters:

$$
\mathrm{Ex}_{\text {work }}=\mathrm{W}
$$

There is exergy destruction in operational processes due to its irreversibilities, the thermodynamic efficiency is associated with the amount of exergy loss. For measuring these losses, process exergy efficiency $(\Psi)$ is formulated. This term is defined as an indicator to determine the degree of used exergy, given by Equation (11):

$$
\Psi=1-\left(\frac{\text { Exergy loss }}{\text { Exergy input }}\right)
$$

Sorin et al. [23] mentioned that it is possible to perform the exergy balance considering all incoming and out-going streams in a defined system. The total exergy input of any real process/system is ever higher than its output. The above is related to the fact that always an amount of exergy is irreversibly lost within the system.

\section{Results}

The chemical composition of lemongrass oil used in process 1 is summarized in Table 1 . This raw material reports high content of moisture, and organic compounds as myrcene, undecyne, nerol, geranial, among other [24]. These substances are the key compounds in the lemongrass extract and are used to guarantee the nanosize of the $\mathrm{TiO}_{2}$ nanoparticles. The oil content in the lemongrass is about $1.10 \%$ of the total mass while the moisture and solid contents are approximately $71.23 \%$ and $27.67 \%$, respectively. The above implies that the oil extraction method has to be highly efficient to reach acceptable/required yields. Most of the solid contents in lemongrass is cellulosic biomass, therefore it was assumed (for simulation purpose) that all solid content is cellulose.

Table 1. Chemical composition of lemongrass dry basis.

\begin{tabular}{cc}
\hline Compound & Average Concentration \\
\hline B-Myrcene & $5.5 \%$ \\
3-Undecyne & $3.2 \%$ \\
Neral & $30.5 \%$ \\
Geranial & $42.5 \%$ \\
Nerol & $3.5 \%$ \\
Others & $14.8 \%$ \\
\hline
\end{tabular}

\subsection{Processes Simulation Results}

3.1.1. Simulation of Large-Scale Production of Chitosan Microbeads Modified with $\mathrm{TiO}_{2} \mathrm{Nanoparticles}$ via Green Chemistry

Process simulation flowsheet of large-scale production of chitosan microbeads modified with $\mathrm{TiO}_{2}$ nanoparticles is shown in Figure 4. And the pressure, temperature, composition and flows of main process streams are shown in Table 2. As is described in Section 2.2, the system is composed of three sections: (1) Lemongrass oil extraction; (2) $\mathrm{TiO}_{2}$ nanoparticles synthesis, and (3) $\mathrm{CMTiO}_{2}$ production. For subprocess (1), stream 1 represents the inlet flow of the main feedstock (lemongrass). This stream is sent to washing and drying stages for cellulosic material removal and moisture reduction, respectively. After feedstock cleaning, the material is sent to a crusher unit for size-reduction. The above is performed with the aim of increasing the surface contact between the lemongrass and the extraction media (water). The liquid-solid extraction (infusion stage) is developed by a heating-sedimentation stage where the oil extract is separated in the upper site of the unit while the residual solids remain at the bottom. The oil extract is obtained with high moisture content $(99 \% \mathrm{w} / \mathrm{w})$ so the stream passes 
through an evaporation unit to reduce the water content close to $3 \% \mathrm{w} / \mathrm{w}$. Finally, the oil extract is cooled until $28^{\circ} \mathrm{C}$, and it is stored. Subprocess (2) starts with the preparation of TTIP solution and the hydrolysis reaction where the $\mathrm{TiO}_{2}$ nanoparticles are synthesized (see stream 39). In the case of subprocess (3), this stage starts with the production of the chitosan gel considering inlet flow according to the composition of stream 43. Stream 39 is added to the mixing tank where the $\mathrm{CMTiO}_{2}$ are formed maintaining the required proportion of $1: 1$ for Chitosan and $\mathrm{TiO}_{2}$, respectively. Finally, the product obtained with a flow of $232.03 \mathrm{~kg} / \mathrm{h}$ according to stream 56 .

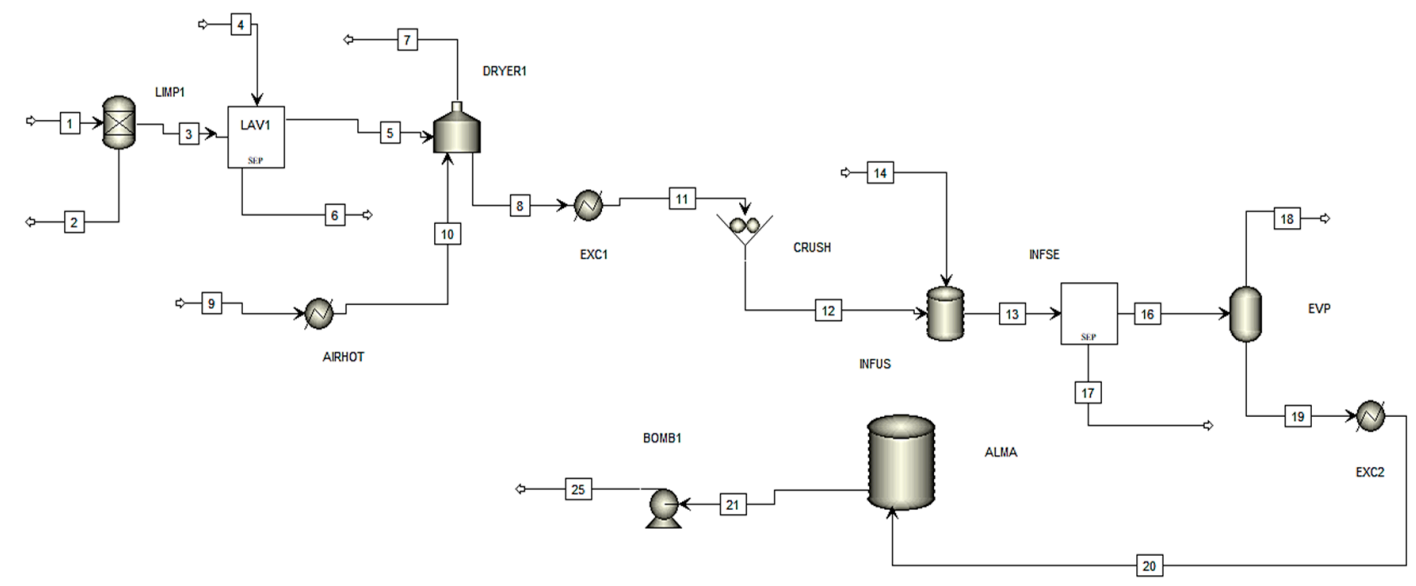

(a)

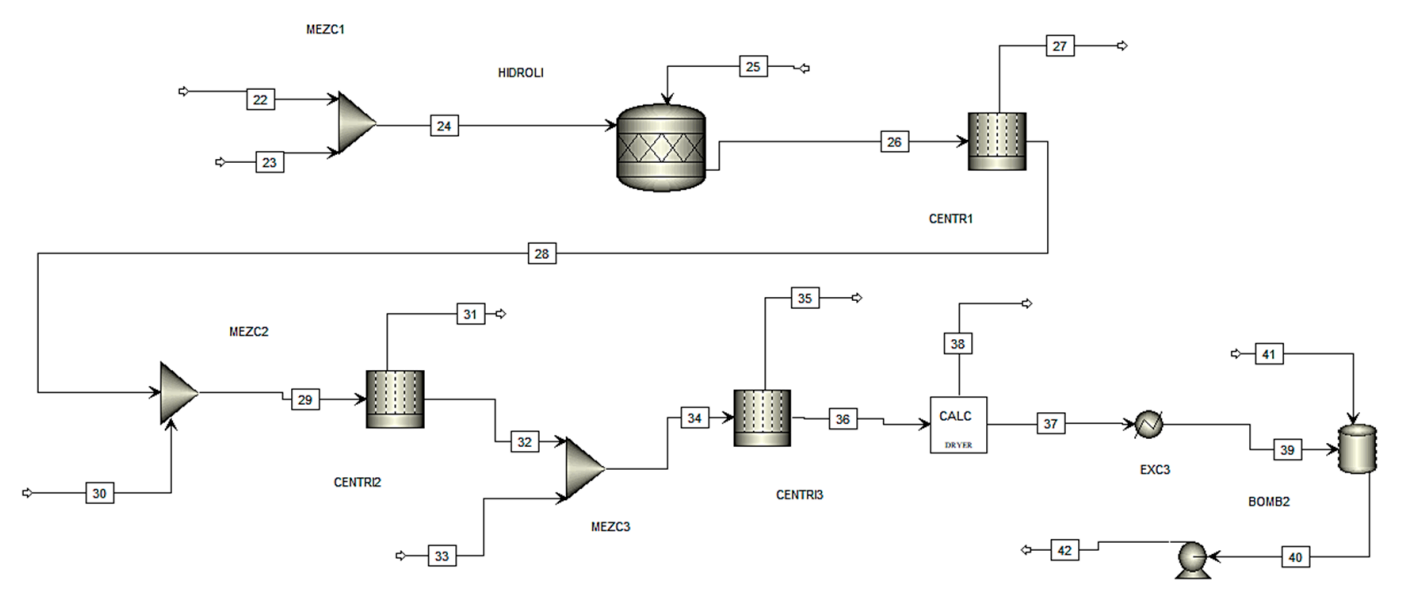

(b)

Figure 4. Cont. 


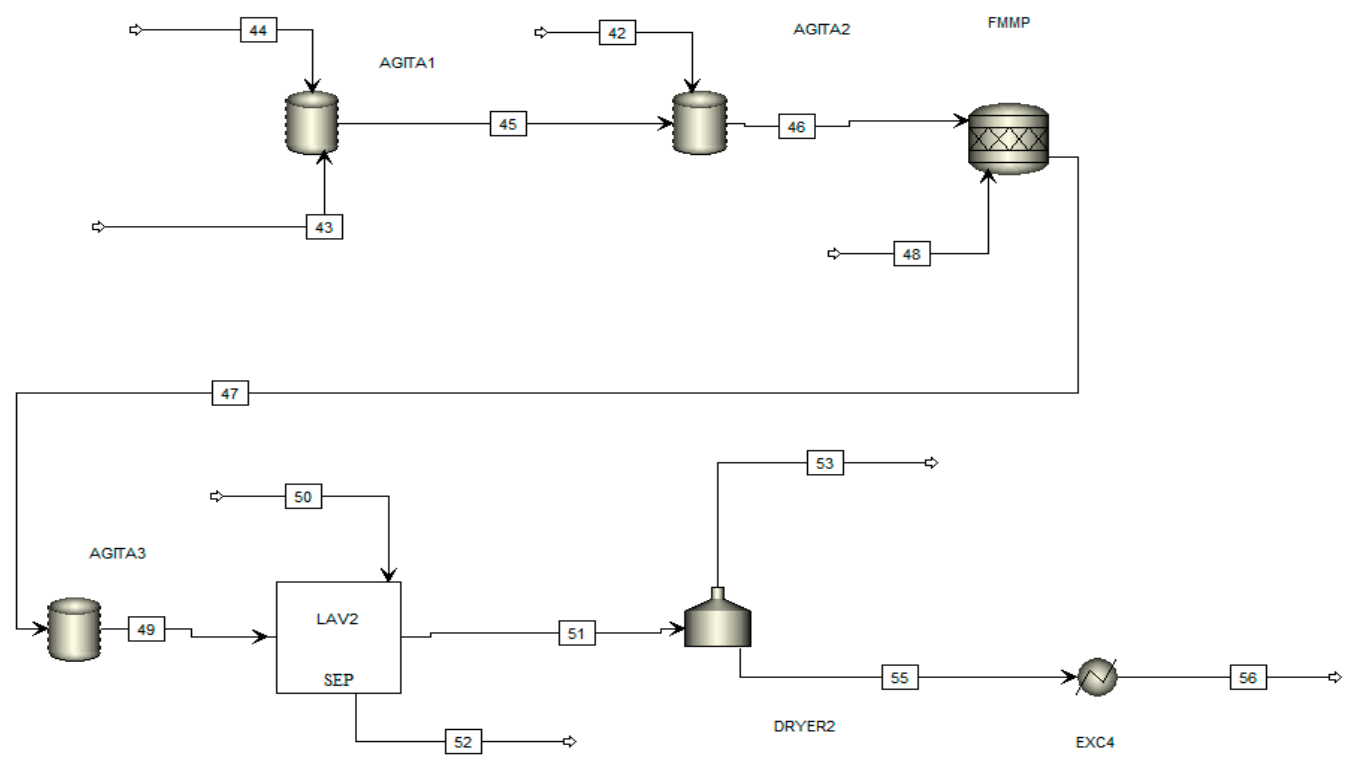

(c)

Figure 4. Process flowsheet of large-scale production of chitosan microbeads modified with $\mathrm{TiO}_{2}$ nanoparticles via a green chemistry method: (a) Lemongrass oil extraction (b) $\mathrm{TiO}_{2}$ nanoparticles synthesis; (c) chitosan microbeads production.

Table 2. Main process streams for Chitosan microbeads modified with $\mathrm{TiO}_{2}$ nanoparticles.

\begin{tabular}{cccccccc}
\hline Streams & $\mathbf{1}$ & $\mathbf{1 9}$ & $\mathbf{2 2}$ & $\mathbf{3 9}$ & $\mathbf{4 3}$ & $\mathbf{4 8}$ & $\mathbf{5 6}$ \\
\hline Temperature (K) & 301.15 & 373.15 & 301.15 & 823.15 & 301.15 & 301.15 & 301.15 \\
Pressure (kPa) & 101.32 & 101.32 & 101.32 & 101.32 & 101.32 & 101.32 & 101.32 \\
& \multicolumn{7}{c}{ Component mass flow $(\mathrm{kg} / \mathrm{h})$} \\
3-Myrcene & 2.04 & 0.47 & 0.00 & 0.00 & 0.00 & 0.00 & 0.00 \\
3-Undecyne & 1.19 & 0.55 & 0.00 & 0.00 & 0.00 & 0.00 & 0.00 \\
Gerenial & 27.10 & 22.46 & 0.00 & 0.00 & 0.00 & 0.00 & 0.00 \\
Nerol & 1.28 & 1.086 & 0.00 & 0.00 & 0.00 & 0.00 & 0.00 \\
Cellulose & 1882.97 & 0.00 & 0.00 & 0.00 & 0.00 & 0.00 & 0.00 \\
Water & 1466.9 & 608.58 & 0.00 & 0.00 & 3782.31 & $17,367.7$ & 0.00 \\
TTIP & 0.00 & 0.00 & 592.90 & 0.00 & 0.00 & 0.00 & 0.00 \\
TiO 2 & 0.00 & 0.00 & 0.00 & 154.84 & 0.00 & 0.00 & 154.84 \\
Chitosan & 0.00 & 0.00 & 0.00 & 0.00 & 77.20 & 0.00 & 77.20 \\
NaOH & 0.00 & 0.00 & 0.00 & 0.00 & 0.00 & 1929.75 & 0.00 \\
Total & 3381.47 & 633.15 & 592.90 & 154.84 & 3859.50 & $19,297.50$ & 232.03 \\
\hline
\end{tabular}

3.1.2. Simulation of Large-Scale Production of Chitosan Microbeads Modified with $\mathrm{TiO}_{2}$ and Magnetite Nanoparticles

The simulation for the second processing route of bio-adsorbents production was performed based on general mass/energy balances, and operational conditions obtained from literature and lab experiments. Figure 5 shows the simulated process flowsheet of large-scale production of chitosan microbeads modified with $\mathrm{TiO}_{2}$ nanoparticles and magnetite. Table 3 summarizes the main streams and operational conditions of this process. As it was described, this designed system is constituted by two main subprocesses: (1) Magnetite nanoparticles synthesis, and (2) chitosan microbeads production (with nanoparticles modification). For magnetite nanoparticles synthesis, stream 1 and 2 represent the inlet flow of main feedstocks: $\mathrm{FeCl}_{2} \cdot 4 \mathrm{H}_{2} \mathrm{O}$ and $\mathrm{FeCL}_{3} \cdot 6 \mathrm{H}_{2} \mathrm{O}$, respectively. The reaction between these iron chlorides and $\mathrm{NaOH}$ generates magnetite (desired product) along with hematite, water and sodium chloride. For simulation purpose, it was assumed that all produced hematite is magnetite. After reaction stage, the stream is sent to separations processes where all impurities are removed from 
the product. The magnetic properties of these nanoparticles allow separating them using a magnetic field or a magnet [19]. Finally, the dried and purified magnetite nanoparticles are sent to the second subprocess, the chitosan microbeads modified with the nanoparticles $\left(\mathrm{TiO}_{2}\right.$ and magnetite) are sent to purification stage where the desired product is obtained dried and with high purity with a mass flow rate of $307.86 \mathrm{~kg} / \mathrm{h}$.

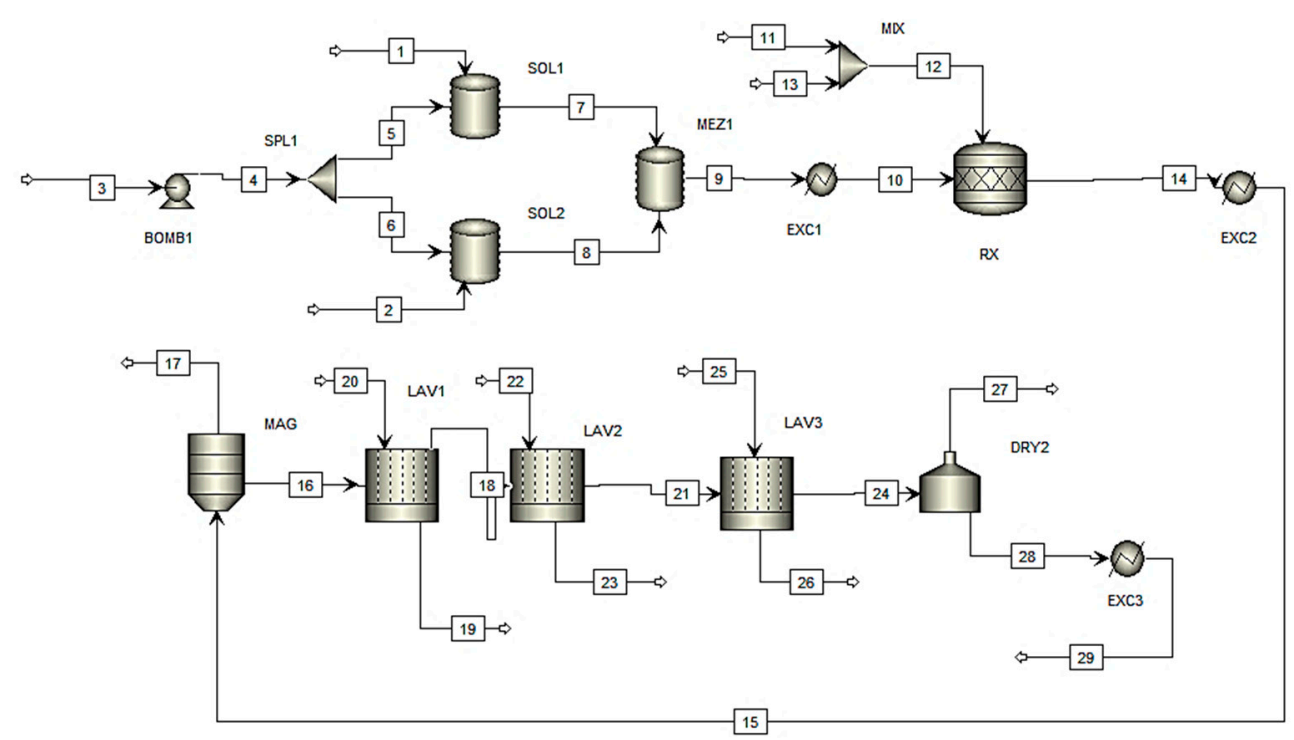

(a)

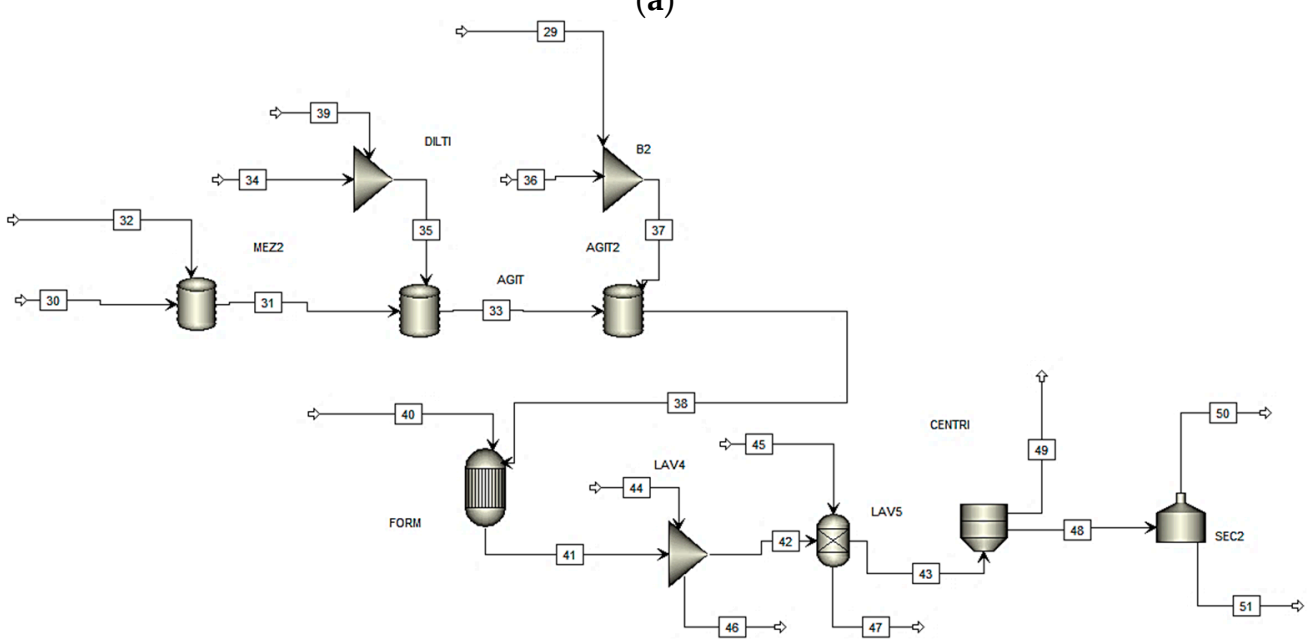

(b)

Figure 5. Process flowsheet of Large-scale production of chitosan microbeads modified with $\mathrm{TiO}_{2}$ and magnetite nanoparticles: (a) Magnetite nanoparticles synthesis; (b) chitosan microbeads with modifications subprocess. 
Table 3. Main process streams for chitosan microbeads modified with $\mathrm{TiO}_{2}$ and magnetite nanoparticles.

\begin{tabular}{|c|c|c|c|c|c|c|c|}
\hline Streams & 1 & 2 & 11 & 29 & 30 & 34 & 51 \\
\hline Temperature (K) & 301.15 & 301.15 & 301.15 & 301.15 & 301.15 & 301.15 & 301.15 \\
\hline Pressure $(\mathrm{kPa})$ & 101.32 & 101.32 & 101.32 & 101.32 & 101.32 & 101.32 & 101.32 \\
\hline \multicolumn{8}{|c|}{ Component mass flow $(\mathrm{kg} / \mathrm{h})$} \\
\hline Water & 0.00 & 0.00 & 0.00 & 0.00 & $10,907.70$ & 0.00 & 0.00 \\
\hline $\mathrm{FeCl}_{3} \cdot 6 \mathrm{H}_{2} \mathrm{O}$ & 200.00 & 0.00 & 0.00 & 4.00 & 0.00 & 0.00 & 2.87 \\
\hline $\mathrm{FeCl}_{2} \cdot 4 \mathrm{H}_{2} \mathrm{O}$ & 0.00 & 79.17 & 0.00 & 7.09 & 0.00 & 0.00 & 5.08 \\
\hline $\mathrm{NaOH}$ & 0.00 & 0.00 & 134.23 & 0.00 & 0.00 & 0.00 & 0.00 \\
\hline Magnetite & 0.00 & 0.00 & 0.00 & 83.94 & 0.00 & 0.00 & 60.24 \\
\hline $\mathrm{NaCl}$ & 0.00 & 0.00 & 0.00 & 0.01 & 0.00 & 0.00 & 0.01 \\
\hline Chitosan & 0.00 & 0.00 & 0.00 & 0.00 & 222.607 & 0.00 & 159.74 \\
\hline $\mathrm{TiO}_{2}$ & 0.00 & 0.00 & 0.00 & 0.00 & 0.00 & 111.35 & 79.90 \\
\hline Acetic acid & 0.00 & 0.00 & 0.00 & 0.00 & 0.00 & 0.00 & 0.00 \\
\hline Total & 200.00 & 79.17 & 134.23 & 95.05 & $11,130.30$ & 111.35 & 307.86 \\
\hline
\end{tabular}

\subsubsection{Simulation of Large-Scale Production of Chitosan Microbeads Modified with Thiourea}

The simulation of the third processing route was developed according to the subprocess stage for chitosan microbeads production described for $\mathrm{CMTiO}_{2}$ and $\mathrm{CMTiO}_{2}-\mathrm{Mag}$ processes. In this case, the modification of the microbeads does not require the synthesis of any nanoparticles because the thiourea is introduced to the process as an available raw material. After this stage, the stream is sent to microbeads production and purification stages. Table 4 reports the main mass flows and operational conditions of this process. Figure 6 shows the simulated process flowsheet of large-scale production of chitosan microbeads modified thiourea. Finally, in this process alternative are produced $155.23 \mathrm{~kg} / \mathrm{h}$ of chitosan microbeads modified with thiourea according to stream 13.

Table 4. Main process streams for chitosan microbeads modified with thiourea.

\begin{tabular}{cccccccc}
\hline Streams & $\mathbf{1}$ & $\mathbf{2}$ & $\mathbf{3}$ & $\mathbf{6}$ & $\mathbf{7}$ & $\mathbf{1 1}$ & $\mathbf{1 3}$ \\
\hline Temperature $(\mathrm{K})$ & 301.15 & 301.15 & 301.15 & 301.15 & 301.15 & 301.15 & 301.15 \\
Pressure $(\mathrm{kPa})$ & 101.32 & 101.32 & 101.32 & 101.32 & 101.32 & 101.32 & 101.32 \\
& \multicolumn{7}{c}{ Component mass flow $(\mathrm{kg} / \mathrm{h})$} \\
Water & 0.00 & $2,857.54$ & 0.00 & $34,520.80$ & $37,452.40$ & $53,653.80$ & 0.00 \\
Chitosan & 77.61 & 0.00 & 0.00 & 0.00 & 77.61 & 0.00 & 77.61 \\
Thiourea & 0.00 & 0.00 & 77.61 & 0.00 & 77.61 & 0.00 & 77.61 \\
NaOH & 0.00 & 0.00 & 0.00 & 1700.40 & 1535.8 & 0.00 & 0.01 \\
Sodium acetate & 0.00 & 0.00 & 0.00 & 0.00 & 337.60 & 0.00 & 0.00 \\
Acetic acid & 0.00 & 274.13 & 0.00 & 0.00 & 0.00 & 0.00 & 0.00 \\
Total & 77.61 & 3104.67 & 77.61 & $36,221.20$ & 39481.10 & $53,653.80$ & 155.23 \\
\hline
\end{tabular}

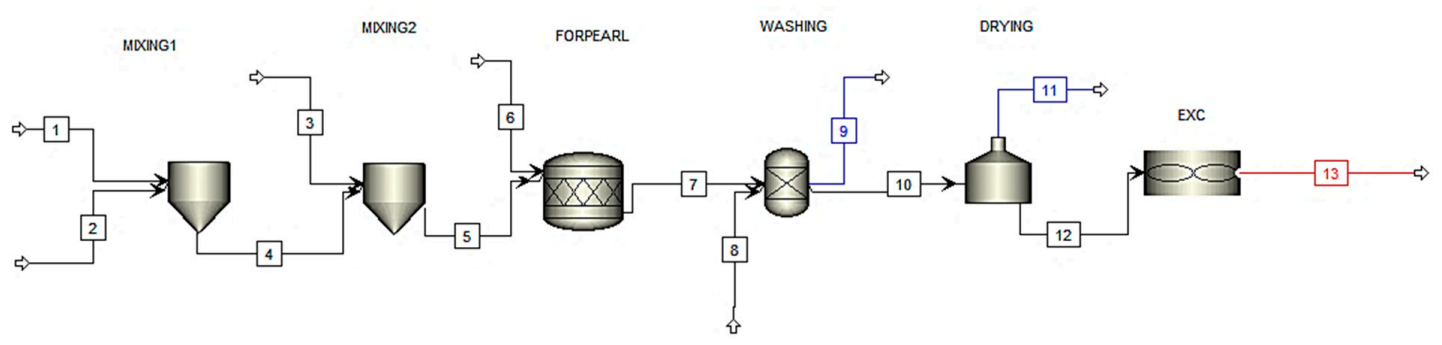

Figure 6. Process flowsheet of large-scale production of chitosan microbeads modified with thiourea.

\subsection{Exergy Analysis of the Routes Simulated}

These large-scale production processes can be generally divided into two main stages: nanoparticles preparation and chitosan microbeads formation. Considering the results of simulations and composition of each stream, chemical and physical exergies were estimated. Table 5 shows the estimated and reported chemical exergies of main components for bio-adsorbent processing routes. 
Table 5. Chemical exergy of main components for bio-adsorbent production processes.

\begin{tabular}{cccc}
\hline Component & Chemical Exergy (MJ/kmol) & Component & Chemical Exergy (MJ/kmol) \\
\hline Myrcene & 9670.10 & NaOH & 74.90 \\
Undecyne & $11,397.10$ & Magnetite & 116.30 \\
Gerenial & $9,708.60$ & Thiourea & 112.10 \\
Nerol & $10,348.10$ & $\mathrm{TiO}_{2}$ & 21.73 \\
TTIP & $7,141.20$ & Water & 0.90 \\
Chitosan & $12,462.78$ & Acetic acid & 907.20 \\
\hline
\end{tabular}

The higher chemical exergies correspond to those compounds with the longest carbon chains in its molecular structures (undecyne, myrcene and chitosan). Chemical exergy for common components as water, $\mathrm{NaOH}$, or acetic acid was found in literature [25]. Table 6 reports the results obtained for exergy performance indicators for each processing route.

Table 6. Results for exergy performance of each processing route.

\begin{tabular}{ccccc}
\hline Process & $\begin{array}{c}\text { Irreversibilities } \\
\mathbf{( M J} / \mathbf{h})\end{array}$ & $\begin{array}{c}\text { Exergy } \\
\text { Efficiency } \mathbf{( \% )}\end{array}$ & $\begin{array}{c}\text { Exergy of } \\
\text { Residues } \mathbf{( M J} / \mathbf{h})\end{array}$ & $\begin{array}{c}\text { Exergy Utilities } \\
\mathbf{( M J} / \mathbf{h})\end{array}$ \\
\hline $\mathrm{CMTiO}_{2}$ & $181,665.63$ & 0.04 & $144,445.08$ & $91,033.74$ \\
$\mathrm{CMTiO}_{2}-\mathrm{Mag}$ & $216,795.71$ & 2.83 & $182,698.34$ & $88,030.46$ \\
$\mathrm{CMThi}^{2}$ & $116,991.60$ & 2.50 & $33,654.48$ & $105,964.41$ \\
\hline
\end{tabular}

$\mathrm{CMTiO}_{2}$ route presents the lowest exergy efficiency performance with a $0.04 \%$. For $\mathrm{CMTiO}_{2}-\mathrm{Mag}$ and CMThi processes were obtained a corresponding exergy efficiency of $2.83 \%$ and $2.50 \%$, respectively. From a general viewpoint, the performance of the exergy efficiency was significantly low for all bio-adsorbent processes. This result implies that these designs might require technological improvements to reach better exergy and energy performances. In this sense, $\mathrm{CMTiO}_{2}$ requires special attention due to its exergy efficiency shows that almost $100 \%$ of the inlet exergy is lost through the operation.

Figure 7 shows the exergy destruction of each bio-adsorbent processing route. The process with higher irreversibilities is $\mathrm{CMTiO}_{2}$-Mag with an exergy flow of $182,698.34 \mathrm{MJ} / \mathrm{h}$, followed by $\mathrm{CMTiO}_{2}$ route with destroyed exergy of $144,445.08 \mathrm{MJ} / \mathrm{h}$. The performance of this parameter is congruent respect to exergy efficiencies obtained for all processes. For $\mathrm{CMTiO}_{2}$ route, it was found that the stage with the highest irreversibilities was the separation train. This stage is composed of three consecutive centrifuges representing approximately $53.00 \%$ of total irreversibilities for this process. The use of other separation technologies may contribute to reduce exergy losses. For the case of $\mathrm{CMTiO}_{2}-\mathrm{Mag}$ route, it was obtained that microbeads-drying unit was the stage with the highest irreversibilities with a contribution of $41.05 \%$, followed by washing unit in the separation stage (see "Lav4" in Figure 5b) with a $24.20 \%$. In the case of CMThi route, drying unit was the stage with the highest exergy destruction representing $92.48 \%$ of total irreversibilities. The above results (for all cases) imply that these designs require better/improved separation technologies/stages to avoid several irreversibilities. This also could contribute to obtaining higher exergy efficiencies for each process. 


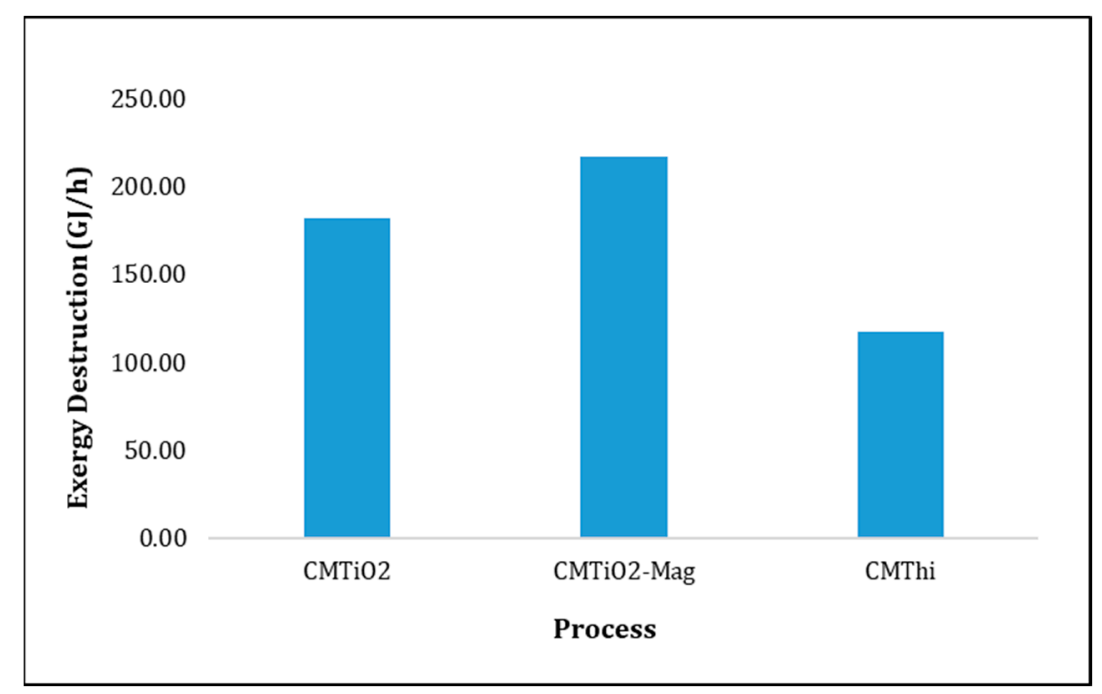

Figure 7. Comparison of exergy destruction for each processing route.

On the other hand, the exergy of residues was higher for $\mathrm{CMTiO}_{2}-\mathrm{Mag}$ route, which was expected due to this process presents higher mass inventory respect to the other processing routes. Figure 8 shows the exergy of residues for each assessed process. CMThi process destroys less exergy due to residues with a flow of $33,654.48 \mathrm{MJ} / \mathrm{h}$, while for $\mathrm{CMTiO}_{2}$ and $\mathrm{CMTiO}_{2}-\mathrm{Mag}$ were obtained exergy flows of $144,405.08 \mathrm{MJ} / \mathrm{h}$ and 182,698.34 MJ/h, respectively.

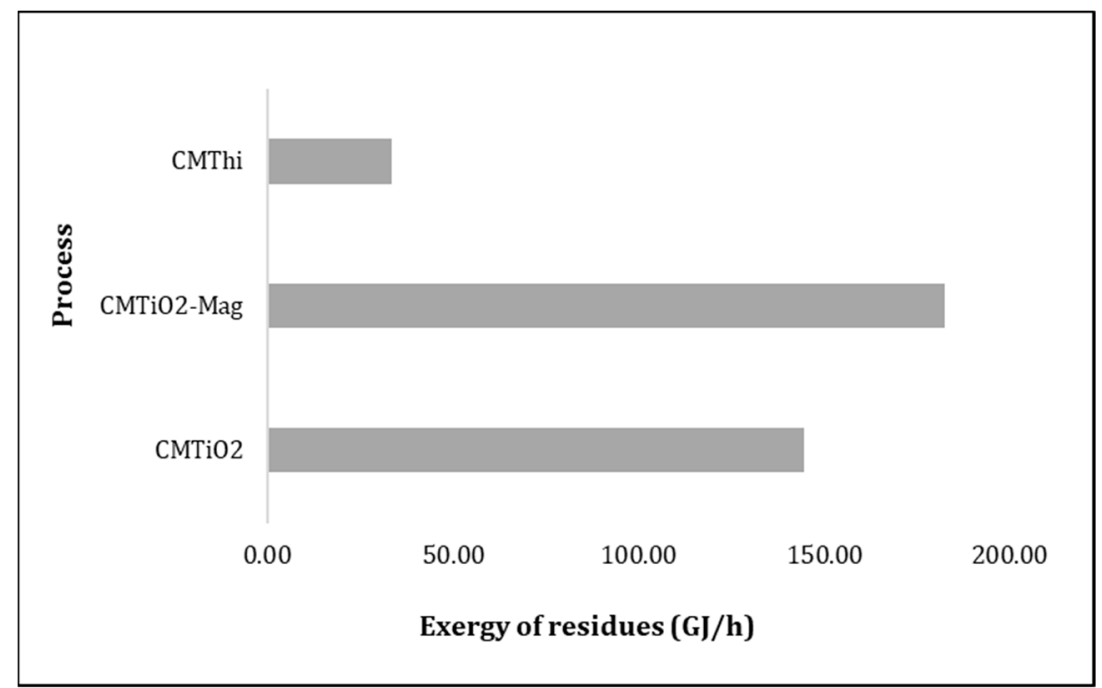

Figure 8. Comparison of exergy of residues for each processing route.

Finally, the exergy of utilities was estimated for each processing route. Figure 9 shows the comparison of this parameter for each bio-adsorbent processing route. The results for exergy of utilities present a similar performance for the three alternatives, obtaining an exergy flow of $91,033.74 \mathrm{MJ} / \mathrm{h}$ for $\mathrm{CMTiO}_{2}, 88,030.46 \mathrm{MJ} / \mathrm{h}$ for $\mathrm{CMTiO}_{2}-\mathrm{Mag}$, and 105,964.41 MJ/h for CMThio. For the case of $\mathrm{CMTiO}_{2}-\mathrm{Mag}$ route, drying unit was the most significant stage representing an around $99 \%$ of the total exergy by utilities for this process. The above result indicates that this unit probably has important energy requirements that implies a high demand of industrial utilities. In this sense, the application of process optimization techniques could contribute to decrease the energy requirements, or obtain a better energy distribution. For $\mathrm{CMTiO}_{2}$ process was found that hydrolysis reactor is a critical stage due to the most of exergy utility is consumed in this unit with a contribution of $47.22 \%$ of the total. It is 
explained by studying the thermodynamics of this reaction (hydrolysis of TTIP) because it is highly exothermic, thus, a cooling system is needed to maintain the reaction temperature constant.

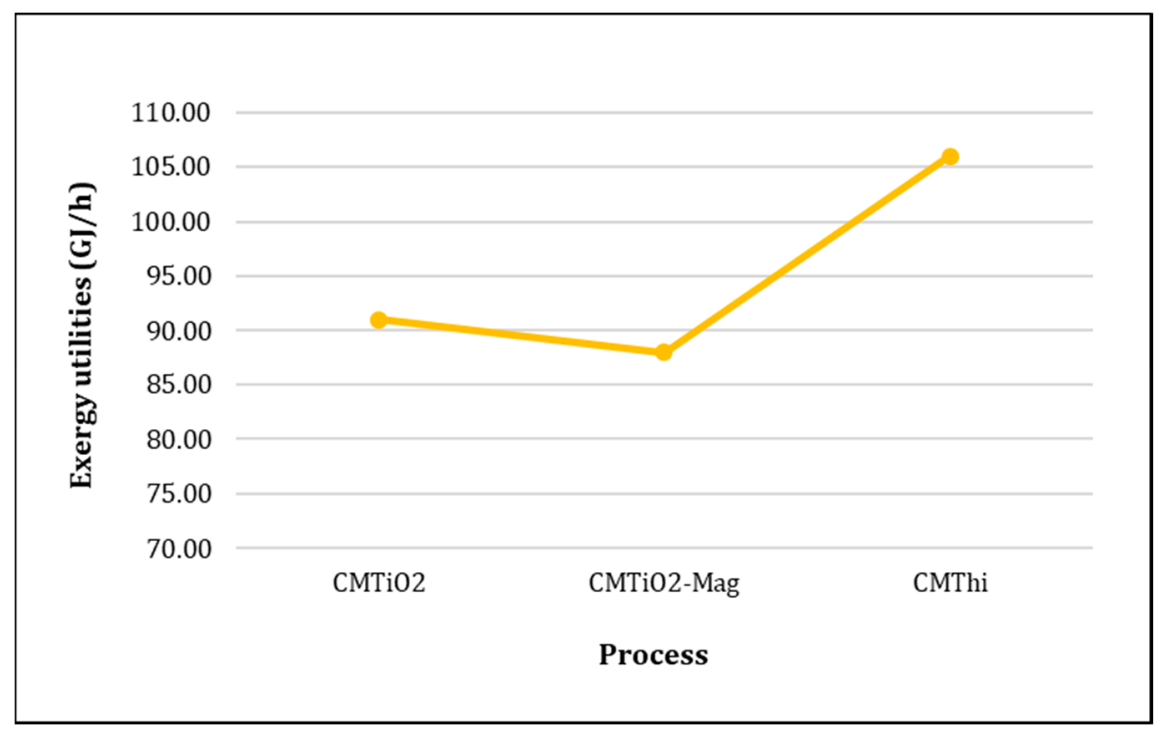

Figure 9. Comparison of exergy utilities for each processing route.

As described by $\mathrm{CMTiO}_{2}$-Mag route, for $\mathrm{CMThio}$ alternative, the drying stage was also the most critical unit for exergy of utilities parameter with an exergy flow of 105,942.41 MJ/h which represents almost a 100\% of the total. This result confirms the described behavior for exergy destruction performance which was previously explained for this bio-absorbent route.

\section{Conclusions}

Exergy analysis was used for the comparative evaluation of emerging alternatives of chitosan-based bio-absorbent production. The exergy analysis results were not conclusive for the selection of a promising alternative given the similar values obtained for the exergy efficiencies of the three routes evaluated $(0.04 \%, 2.83 \%$ and $2.50 \%)$, being the production of chitosan microbeads modified with $\mathrm{TiO}_{2}$ and magnetite nanoparticles, the route with the highest overall exergy efficiency $(2.83 \%)$. However, the analysis presented in this work allowed to diagnose the emerging production processes from the exergetic point of view as sustainability criteria related to resources conservation. All the routes evaluated showed a similar poor exergetic performance. This behavior of the topologies assessed is related to the huge amount of water that are lost (and not recovered) in the bio-adsorbent purification stages along with the low energetic efficiency of the separation units. The use of a neutralization unit instead of washing stages might contribute to save large quantities of water, and improve the exergy efficiency of the processes. Route 2 also showed the highest irreversibilities of the three cases evaluated. The highest exergy destruction for production of chitosan microbeads modified with $\mathrm{TiO}_{2}$ and magnetite nanoparticles was found in the microbeads-drying unit, but also, this alternative presents the lowest exergy flow associated to utilities. On the other hand, $\mathrm{CMTiO}_{2}$ route presented the lowest exergy efficiency $(0.04 \%)$, and an exergy loss of $181,665.63 \mathrm{MJ} / \mathrm{h}$. For the case of CMThio route, it was determined that this process has high energy demands in the drying stage, resulting in a high exergy flow by utilities. For all routes evaluated is recommendable to apply process optimization techniques as mass and energy integration to decrease the requirement of utilities for separation/purification stages. For future work, it is recommended to develop studies related to economic and environmental impacts of the routes evaluated in order to obtain more sustainability parameters for selection of the most promising alternative under parameters evaluated. 
Author Contributions: S.M.-H., A.H.-B. and A.G.-D. conceived and designed the paper, and wrote the Introduction and Materials and Methods. S.M.-H. and A.G.-D. wrote the Results and prepared figures and tables. Discussions and Conclusions were the collective work of all authors. The writing-review \& editing was performed by A.G.-D. and A.H.-B., A.G.-D. supervised the development of this paper.

Funding: This research was funded by the Colombian Administrative Department of Science, Technology and Innovation COLCIENCIAS, code 110748593351 CT069/17. The APC was funded by COLCIENCIAS.

Acknowledgments: The authors thank to the Colombian Administrative Department of Science, Technology and Innovation COLCIENCIAS and the Doctoral Engineering program of the University of Cartagena, for its support with project "Removal of polycyclic aromatic hydrocarbons (PAHs), present in coastal waters Cartagena bay by using shrimp exoskeleton as a source of nanoparticle-modified bioadsorbents", code 1107748593351 CT069/17.

Conflicts of Interest: The authors declare no conflict of interest. The funders had no role in the design of the study; in the collection, analyses, or interpretation of data; in the writing of the manuscript, or in the decision to publish the results.

\section{References}

1. Bhojwani, S.; Topolski, K.; Mukherjee, R.; Sengupta, D.; El-Halwagi, M.M. Technology review and data analysis for cost assessment of water treatment systems. Sci. Total Environ. 2019, 651, 2749-2761. [CrossRef]

2. De Gisi, G.; Lofrano, M.; Grassi, M.; Notarnicola, M. Characteristics and adsorption capacities of low-cost sorbents for wastewater treatment: A review. Sustain. Mater. Technol. 2016, 9, 10-40. [CrossRef]

3. Sun, X.; Liu, Q.; Yang, L.; Liu, H. Chemically modified magnetic chitosan microspheres for Cr (VI) removal from acidic aqueous solution. Particuology 2016, 26, 79-86. [CrossRef]

4. Zhou, L.; Liu, J.; Liu, Z. Adsorption of platinum (IV) and palladium (II) from aqueous solution by thiourea-modified chitosan microspheres. J. Hazard. Mater. 2009, 172, 39-446. [CrossRef] [PubMed]

5. Righi, S.; Baioli, F.; Dal Pozzo, A.; Tugnoli, A. Integrating Life Cycle Inventory and Process Design Techniques for the Early Estimate of Energy and Material Consumption Data. Energies 2018, 11, 970. [CrossRef]

6. Hendershot, D. Green chemistry and process safety. J. Chem. Health Saf. 2015, 22, 39. [CrossRef]

7. Wang, P.; Lombi, E.; Zhao, F.; Kopittke, P. Nanotechnology: A New Opportunity in Plant Sciences. Trends Plant Sci. 2016, 21, 699-712. [CrossRef]

8. Karimi, M.H.; Mahdavinia, G.R.; Massoumi, B.; Baghban, A.; Saraei, M. Ionically crosslinked magnetic chitosan/K-carrageenan bioadsorbents for removal of anionic eriochrome black-T. Int. J. Boil. Macromol. 2018, 113, 361-375. [CrossRef]

9. Meramo-Hurtado, S.; Bonfante, H.; De Avila-Montiel, G.; Herrera-Barros, A.; González-Delgado, A. Environmental assessment of a large-scale production of $\mathrm{TiO}_{2}$ nanoparticles via green chemistry. Chem. Eng. Trans. 2018, 70, 1063-1068.

10. Ojeda, K.; Sanchez, E.; Kafarov, V. Sustainable ethanol production from lignocellulosic biomass-Application of exergy analysis. Energy 2011, 36, 2119-2128. [CrossRef]

11. Peralta-Ruiz, Y.; Gonzalez-Delgado, A.; Kafarov, V. Evaluation of alternatives for microalgae oil extraction based on exergy analysis. Appl. Energy 2013, 101, 226-236. [CrossRef]

12. Aghbashlo, M.; Mandegari, M.; Tabatabaei, M.; Farzad, S.; Mojarab Soufiyan, M.; Görgens, J.F. Exergy analysis of a lignocellulosic-based biorefinery annexed to a sugarcane mill for simultaneous lactic acid and electricity production. Energy 2018, 149, 623-638. [CrossRef]

13. Meramo-Hurtado, S.; Ojeda-Delgado, K.; Sánchez-Tuíran, E. Exergy analysis of bioethanol production from rice residues. Comtemp. Eng. Sci. 2018, 11, 467-474. [CrossRef]

14. Restrepo-Serna, D.L.; Martinez-Ruano, J.A.; Cardona-Alzate, C.A. Energy Efficiency of Biorefinery Schemes Using Sugarcane Bagasse as Raw Material. Energies 2018, 11, 3474. [CrossRef]

15. Goméz-Ríos, D.; Barrera-Zapata, R.; Ríos-Estepa, R. Comparison of process technologies for chitosan production from shrimp shell waste: A techno-economic approach using Aspen Plus ${ }^{\circledR}$. Food Bioprod. Process. 2017, 103, 49-57. [CrossRef]

16. Bonfante-Álvarez, H.; De Avila-Montiel, G.; Cogollo-Herrera, K.; Herrera-Barros, A.; González-Delgado, A. Evaluation of Five Chitosan Production Routes with Astaxanthin Recovery from Shrimp Exoskeletons. Chem. Eng. Trans. 2018, 70, 1969-1974. [CrossRef]

17. Meramo-Hurtado, S.; Ojeda-Delgado, K.; Sánchez-Tuíran, E. Environmental assessment of a biorefinery: A case study of a purification stage in biomass gasification. Comtemp. Eng. Sci. 2018, 11, 113-120. [CrossRef] 
18. Wang, L.; Yang, Z.; Sharma, S.; Mian, A.; Lin, T.; Tsatsaronis, G.; Maréchal, F.; Yang, Y. A Review of Evaluation, Optimization and Synthesis of Energy Systems: Methodology and Application to Thermal Power Plants. Energies 2018, 12, 73. [CrossRef]

19. Wei, Y.; Han, B.; Hu, X.; Lin, Y.; Wang, X.; Den, X. Synthesis of $\mathrm{Fe}_{3} \mathrm{O}_{4}$ nanoparticles and their magnetic properties. Eng. Procedia 2012, 27, 632-637. [CrossRef]

20. Querol, E.; González-Regueral, B.; Pérez-Benedito, J.L. Practical Approach to Exergy and Thermoeconomic Analyses of Industrial Processes, 1st ed.; Springer: Berlin, Germany, 2013.

21. Wang, J.J.; Yang, K.; Xu, Z.L.; Fu, C. Energy and exergy analyses of an integrated CCHP system with biomass air gasification. Appl. Energy 2015, 142, 317-327. [CrossRef]

22. Abosoglu, A.; Kanoglu, M. Exergetic and thermoeconomic analyses of diesel engine powered cogeneration: Part 1-Formulations. Appl. Therm. Eng. 2009, 29, 234-241. [CrossRef]

23. Sorin, M.; Lambert, J.; Paris, J. Exergy flows analysis in chemical reactors. Chem. Eng. Res. Des. 1998, 76, 389-395. [CrossRef]

24. Tajidin, N.E. Chemical composition and citral content in lemongrass (Cymbopogon citratus) essential oil at three maturity stages. Afr. J. Biotechnol. 2012, 11, 2685-2693. [CrossRef]

25. Kaushik, S.C.; Singh, O.K. Estimation of chemical exergy of solid, liquid and gaseous fuels used in thermal power plants. J. Therm. Anal. Calorim. 2014, 115, 903-908. [CrossRef]

(c) 2019 by the authors. Licensee MDPI, Basel, Switzerland. This article is an open access article distributed under the terms and conditions of the Creative Commons Attribution (CC BY) license (http://creativecommons.org/licenses/by/4.0/). 